\title{
Isothermal and Non-Isothermal Reduction Behaviors of Iron Ore Compacts in Pure Hydrogen Atmosphere and Kinetic Analysis
}

\author{
Abourehab Hammam ${ }^{1,2} \cdot \mathrm{Ying} \mathrm{Li}^{1} \cdot \mathrm{Hao} \mathrm{Nie}^{1} \cdot$ Lei Zan ${ }^{1} \cdot$ Weitian Ding ${ }^{1} \cdot \mathrm{Yao} \mathrm{Ge}^{1} \cdot \mathrm{Meng} \mathrm{Li}^{1}$. \\ Mamdouh Omran ${ }^{1,2,3}$ (D) Yaowei $\mathrm{Yu}^{1}$
}

Received: 18 March 2020 / Accepted: 21 September 2020 / Published online: 29 September 2020

(C) The Author(s) 2020

\begin{abstract}
This study examines the isothermal and non-isothermal reduction behaviors of iron ore compacts in a pure hydrogen atmosphere and compares the results obtained during the reduction process by CO. The different phases accompanying the reduction reactions were identified using X-ray diffraction (XRD) and its morphology was microscopically examined. In isothermal experiments, temperature plays a significant role in the reduction process. At any given temperature, the reduction rate during the initial stages is higher than that during the final stages. The reduction rate in $\mathrm{H}_{2}$ atmosphere was faster than in $\mathrm{CO}$ gas. The comparison of activation energy values suggested that reduction with $\mathrm{H}_{2}$ is more efficient than with $\mathrm{CO}$. At the same temperature, the time required to achieve a certain degree of reduction was lower when using $\mathrm{H}_{2}$ gas than $\mathrm{CO}$ atmosphere. In non-isothermal tests, the heating rate has a significant effect on the reduction rate and reduction extent. At the same heating rate, the degree of reduction was higher in $\mathrm{H}_{2}$ atmosphere than in $\mathrm{CO}$ gas. Based on experimental data, the parameters of reaction kinetics were deduced by application of model-free and model-fitting methods. The reduction in $\mathrm{H}_{2}$ atmosphere was controlled by nucleation model (Avrami-Erofeev model), while the $\mathrm{CO}$ reduction reaction was controlled by gas diffusion.
\end{abstract}

Keywords Hydrogen gas $\cdot$ Isothermal reduction $\cdot$ Non-isothermal reduction $\cdot$ Kinetics and mechanism

\section{Introduction}

Iron and steelmaking sector is one of the most important sectors due its great impact on the global growth, economy, and development. In recent years, the steel production rate has increased sharply [1]. By 2050, steel demand is expected to increase to 1.5 times higher than the current levels in order to meet the needs of a growing population [2,3]. About $70 \%$ of the total steel production relies directly on inputs from coke and coal $[3,4]$. The $\mathrm{CO}_{2}$ emission from iron and steelmaking

Mamdouh Omran

mamdouh.omran@oulu.fi

$\triangle$ Yaowei Yu

Yaoweiyu@shu.edu.cn

1 State Key Laboratory of Advanced Special Steel, Shanghai Key Laboratory of Advanced Ferrometallurgy, School of Materials Science and Engineering, Shanghai University, Shanghai, China

2 Central Metallurgical Research and Development Institute (CMRDI), P.O. Box 87, -Helwan, Cairo, Egypt

3 Process Metallurgy Research Group, Faculty of Technology, University of Oulu, Oulu, Finland was 2.3 billion tons in 2007, while by 2050 it is expected to reach 3.0 billion tons [5]. Nowadays, the main challenges for the steel industry are energy consumption and environmental pollution. Therefore, the growing of the steel sector requires serious attention in order to establish processes that are economically viable and environmentally friendly [6].

Direct reduction (DR) process is one of the promising alternative ironmaking processes to effectively reduce $\mathrm{CO}_{2}$ emissions. Therefore, recently great efforts have been paid to develop DR processes. The natural gas and non-coking coal are main reductants and sources of energy used in these DR processes [7]. In Sweden, three companies, steel manufacturer SSAB, mining company LKAB, and energy company Vattenfall, are exploring the use of hydrogen in steel production processes. This technology is known as Hydrogen Breakthrough Ironmaking Technology (HYBRIT) and aims to totally replace the coke with hydrogen gas $[8,9]$. In view of increasing demand for direct reduced iron in the manufacturing of steel, a good deal of emphasis is being given to promote the study of DR process [10]. Recently, attention has been paid on studying the kinetics and mechanisms of iron oxide reduction in the different gas mixture such as $\mathrm{H}_{2}, \mathrm{CO}$, and $\mathrm{CO}$ / $\mathrm{H}_{2}$ gas mixtures. 
The effect of $\mathrm{H}_{2}-\mathrm{H}_{2} \mathrm{O}$ on the iron ore pellet reduction was isothermally investigated at $700-1100{ }^{\circ} \mathrm{C}$ [11]. The influence of a mixture of CO-CO $-\mathrm{C}_{2}-\mathrm{H}_{2} \mathrm{O}-\mathrm{N}_{2}$ reducing gas was compared with that of a mixture of reducing gas containing only $\mathrm{CO}-\mathrm{CO}_{2}-\mathrm{N}_{2}$. The results indicate that the reduction degree increases with increasing the temperature in both reducing gas atmospheres. Spreitzer et al. [12] indicated that, by increasing $\mathrm{H}_{2}$ content in the reducing atmosphere, the reduction degree of pellets improved, owing to improving the diffusion rate due to hydrogen's small molecular size.

El-Geassy et al. studied the reduction mechanism of iron oxide in $\mathrm{H}_{2} / \mathrm{CO}$ mixtures in a temperature range of 800 to $1100{ }^{\circ} \mathrm{C}$ [13]. They concluded that the reduction with either $\mathrm{CO}$ or $\mathrm{CO} / \mathrm{H}_{2}$ gas mixtures is controlled by mixed mechanism (combination of chemical reaction and gaseous diffusion) with a greater contribution of the gaseous diffusion as the $\mathrm{CO}$ content increases in the gas mixture. El-Geassy investigated the influence of doping with $\mathrm{CaO}$ and/or $\mathrm{MgO}$ on the stepwise reduction of hematite compacts [14]. They found that, during the first and second step $\left(\mathrm{Fe}_{2} \mathrm{O}_{3}-\mathrm{Fe}_{3} \mathrm{O}_{4}\right.$ and $\mathrm{Fe}_{3} \mathrm{O}_{4}-\mathrm{FeO}$ ), the reduction rate increased in its early stages when any doping oxide was used. At later stage (FeO-Fe), the presence of $\mathrm{MgO}$ impeded the reduction process. El-Geassy et al. $[15,16]$ studied the volume change of iron oxide compacts and the influence of gas composition on reduction behavior at 800 to $1100{ }^{\circ} \mathrm{C}$. They found that increased $\mathrm{CO}$ content in the gas mixture had a significant influence on swelling and maximum swelling (224\%) was observed for samples reduced at $900{ }^{\circ} \mathrm{C}$. Decreasing $\mathrm{CO}$ content in the gas mixture led to a decreased in swelling by $24 \%$ in pure $\mathrm{H}_{2}$ atmospheres.

The reduction of iron ore with gas takes place in either two or three stages, depending on the applied temperature. At temperature $>570{ }^{\circ} \mathrm{C}$, hematite is first reduced to magnetite then to wustite in a non-stoichiometric phase $\left(\mathrm{Fe}_{1-\mathrm{y}} \mathrm{O}\right)$ and finally to metallic iron. At temperatures $\leq 570{ }^{\circ} \mathrm{C}$, hematite is reduced to magnetite and then directly transformed into metallic iron [17]. Daniel et al. [18] study the reduction kinetics of hematite iron ore fines by hydrogen gas using a laboratory fluidized bed reactor in a temperature range $873-1073 \mathrm{~K}$. They concluded that the reduction takes place in three steps: $\mathrm{Fe}_{2} \mathrm{O}_{3}-\mathrm{Fe}_{3} \mathrm{O}_{4}$, $\mathrm{Fe}_{3} \mathrm{O}_{4}-\mathrm{FeO}$, and finally $\mathrm{FeO}-\mathrm{Fe}$. Lin et al. [19] were using temperature-programmed reduction (TPR) methods to study the reduction mechanism of iron oxide with hydrogen. They found that reduction takes place in two steps: the first step $\left(\mathrm{Fe}_{2} \mathrm{O}_{3}-\mathrm{Fe}_{3} \mathrm{O}_{4}\right)$ was confirmed by the unimolecular model, while the second step $\left(\mathrm{Fe}_{3} \mathrm{O}_{4}-\mathrm{Fe}\right)$ matched a nucleation twodimensional model according to the Avrami-Erofeev model.

Piotrowski et al. [20] investigated the effect of gas composition on the kinetics of iron oxide reduction by hydrogen. It was found that the reaction rate increases with both temperature and the hydrogen content. The reduction was initially proved to be a surface-controlled process. Once a thin layer of lower oxides (magnetite and wustite) formed on the surface, then the reduction mechanism shifts to control by gas diffusion. Bonalde et al. [21] investigated the reduction kinetics of hematite pellets at $850{ }^{\circ} \mathrm{C}$. The reduction experiments were carried out using $\mathrm{H}_{2}, \mathrm{CO}$, and gas mixture. Reduction rates with $\mathrm{H}_{2}$ were better than with $\mathrm{CO}$. Skorianz [22] studied the reduction behavior of different iron ores with different porosities in a fluidized bed reactor. The reducibility of ores was demonstrated to be in this order: limonitic with the highest porosity hematite then magnetite with low porosity.

During the industrial DR process, the reduction of iron ore happens at variable temperatures (non-isothermal) rather than at a constant temperature (isothermal). Therefore, it is vital to understand the kinetic analysis of non-isothermal conditions, which would be a better choice for non-blast furnace ironmaking, i.e., the DR process and hydrogen metallurgy. The latter in recent years becomes quite popular in the global steel industry and in academic field.

Non-isothermal reduction reaction of $\mathrm{Fe}_{2} \mathrm{O}_{3}$ nanopowder by hydrogen was studied at various heating rates [23]. It was found that the reduction process takes place in the sequence of $\mathrm{Fe}_{2} \mathrm{O}_{3}$ to $\mathrm{Fe}_{3} \mathrm{O}_{4}$ and $\mathrm{Fe}_{3} \mathrm{O}_{4}$ to $\mathrm{Fe}$. The apparent activation energy $E a$ for kinetic analysis was determined using the Kissinger-Akahira-Sunose (KAS) method. During the reduction step $\left(\mathrm{Fe}_{3} \mathrm{O}_{4}\right.$ to $\left.\mathrm{Fe}\right)$, the reduction rate was retarded by sintering of oxide particles leading to an abrupt increase of activation energy. As the volume fraction of the metallic iron increased, the reaction rate accelerated, which can be attributed to the catalytic role of the reduced Fe particles facilitating reduction of the adjacent oxide particles. Jie Dang et al. [24] investigate the reduction of titanomagnetite (TTM) powders by hydrogen gas under a non-isothermal condition by using thermogravimetry (TG). It was found that the reduction of TTM proceeded via a dual-reaction mechanism. The first one was the reduction of TTM to wustite and ilmenite, while the second reaction was the reduction of wustite and ilmenite to metallic iron and titanium dioxide. The calculated apparent activation energies were $90-98$ and $115-132 \mathrm{~kJ} / \mathrm{mol}$ for the first and second reactions, respectively.

Tiernan et al. [25] investigate the reduction kinetics of iron oxide catalysts under non-isothermal conditions. Both temperature-programmed reductions (TPR) and constant rate temperature-programmed reduction (CR-TPR) were utilized. $\mathrm{Fe}_{2} \mathrm{O}_{3}$ was found to reduce to $\mathrm{Fe}$ in two steps: $\mathrm{Fe}_{2} \mathrm{O}_{3}-\mathrm{Fe}_{3} \mathrm{O}_{4}$ and $\mathrm{Fe}_{3} \mathrm{O}_{4}$-Fe. The rate-controlling mechanism was described by the random formation and growth of nuclei. CR-TPR profiles allowed the measurement of apparent activation energies as a function of the reduction extent. For the first step, Ea was found to be $96 \mathrm{~kJ} / \mathrm{mol}$. For the second step, $E a$ decreased from 69 to $59 \mathrm{~kJ} / \mathrm{mol}$ as the reduction proceeded.

The present study aims to investigate the isothermal and non-isothermal reduction kinetics of iron ore fines in a hydrogen atmosphere, comparing the experimental results of $\mathrm{H}_{2}$ with those of $\mathrm{CO}$. The study will predict the kinetics and 
correlate these predictions with the morphological structure to deduce the reduction mechanisms.

\section{Experimental Technique}

\subsection{Materials}

The iron ore fines used in this study were collected from a DR plant (Al-Ezz El-Dekheila Steel Company, Alexandria) in the form of a waste material produced by the transportation and handling of pellets. The sample was characterized using X-ray diffraction (XRD; PW 1730 with $\mathrm{Cu}$ radiation, $\lambda=1.5 \AA$, at $40 \mathrm{kV}$ and $30 \mathrm{~mA}$ ). Figure 1 shows that hematite was the main mineral phase in the sample.

The chemical composition of the sample was identified using X-ray fluorescence (XRF advanced Axios, Netherlands); the results are listed in Table 1. Iron (III) oxide $\left(\mathrm{Fe}_{2} \mathrm{O}_{3}\right)$ was the main oxide in the sample accounting for about 96 wt. $\%$.

Size analysis was conducted for representative sample of iron ore fines to determine the size distribution. A laboratory "Wedag" Ro-tap sieve shaker was employed for dry screening of sample. Shaking was performed at $60 \mathrm{~Hz}$ for $20 \mathrm{~min}$, after which the weight of oversize on sieves was recorded to calculate weight passed and/or retained. The particle size distribution in the iron ore fine sample is shown in Table 2, indicating that more than $60 \%$ of the sample consisted of particles in the $<100 \mu \mathrm{m}$ size range.

The structure of the sample was examined using both a scanning electron microscope (SEM JEOL, JSM-5410, $10 \mathrm{Kv}$ ) and reflected light microscope (RLM, Zeiss Axio Scope A1) as shown in Fig. 2a and b, respectively. The SEM image shows that the structure contains fragments of different shapes and sizes which came out of pellet disintegration and abrasion during pellet transportation and handling. The RLM photomicrograph indicates that the internal
Table 1 Chemical composition of iron ore fine sample

\begin{tabular}{llll}
\hline Elements & wt.\% & Oxides & wt.\% \\
\hline $\mathrm{Fe}_{2} \mathrm{O}_{3}$ & 96.01 & $\mathrm{~K}_{2} \mathrm{O}$ & 0.024 \\
$\mathrm{SiO}_{2}$ & 1.62 & $\mathrm{P}_{2} \mathrm{O}_{5}$ & 0.039 \\
$\mathrm{CaO}$ & 0.977 & $\mathrm{MnO}$ & 0.093 \\
$\mathrm{MgO}$ & 0.099 & $\mathrm{~V}_{2} \mathrm{O}_{5}$ & 0.051 \\
$\mathrm{Al}_{2} \mathrm{O}_{3}$ & 0.655 & $\mathrm{Cr}_{2} \mathrm{O}_{3}$ & 0.021 \\
$\mathrm{TiO}_{2}$ & 0.082 & $\mathrm{SrO}$ & 0.012 \\
$\mathrm{SO}_{3}$ & 0.054 & $\mathrm{NiO}$ & 0.017 \\
$\mathrm{Na}_{2} \mathrm{O}$ & 0.011 & & \\
\hline
\end{tabular}

structure includes a relatively dense matrix with more or less homogeneously distributed pores.

\subsection{Compact Preparation}

In order to ensure that the compacts were of uniform size and shape, iron ore fines were compressed in a stainless steel cylindrical mold. The compacts were created by mixing iron ore fines with $6 \%$ distilled water as a binder. Then, equal weights $(2 \mathrm{~g})$ of the mixture were compressed at $10 \mathrm{~atm}\left(10 \mathrm{~kg} / \mathrm{cm}^{2}\right)$ using a hydraulic press. Compacts with a diameter of $10 \mathrm{~mm}$ and a height of $12 \mathrm{~mm}$ were dried at $110{ }^{\circ} \mathrm{C}$ and kept in a dissector for subsequent analysis.

The total reducible oxygen content $\left(w_{0}\right)$ of iron ore fines was estimated by preliminary reduction experiment at 1100 ${ }^{\circ} \mathrm{C}$ using $\mathrm{H}_{2}$ gas until the weight of the sample reaches constant (Eq. 1). Then, the extent of the reduction at time $t\left(R_{\mathrm{t}} \%\right)$ was calculated using Eq. 2.

$w_{0}=w_{\mathrm{i}}-w_{\mathrm{f}}$

$R_{\mathrm{t}}=\frac{\left(w_{\mathrm{i}}-w_{\mathrm{t}}\right)}{w_{0}} * 100$

where $w_{\mathrm{i}}$ is the weight of the sample at zero time, $w_{\mathrm{t}}$ is the
Fig. 1 X-ray diffraction of iron ore fine sample

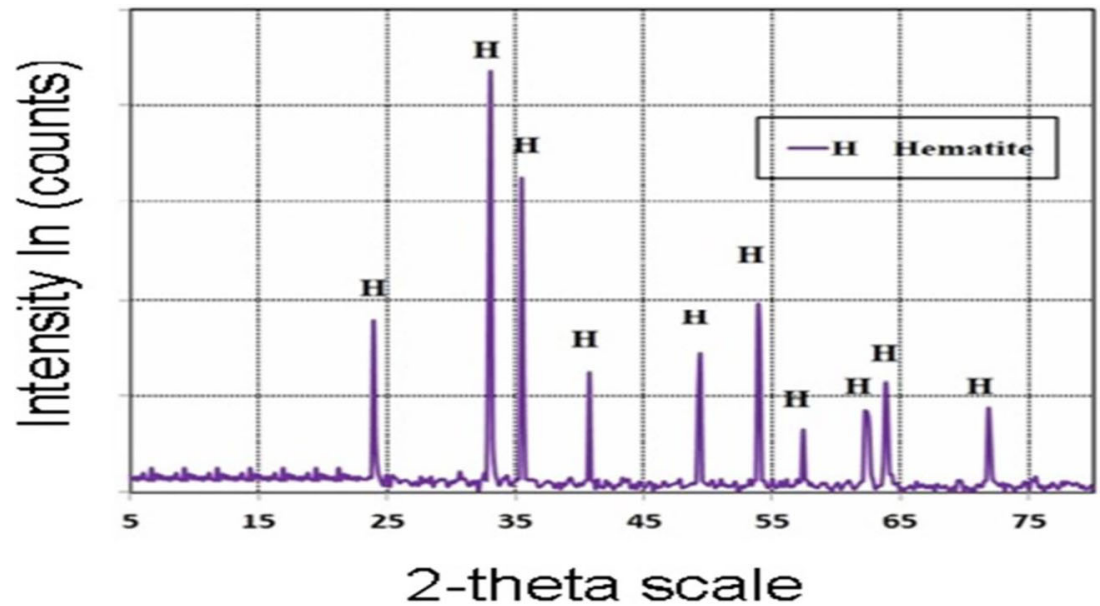


Table 2 Particle size distribution of iron ore fines (mass \%)

\begin{tabular}{llllllll}
\hline & \multicolumn{3}{l}{ Size fraction/ $\mathrm{m}$} & & \multirow{2}{*}{ Total } \\
\cline { 2 - 7 } & $(-250+205)$ & $(-205+150)$ & $(-150+105)$ & $(-105+75)$ & $(-75+45)$ & $(-45)$ & \\
\hline Mass\% & 7.47 & 10.48 & 16.74 & 34.52 & 20.54 & 10.25 & 100 \\
\hline
\end{tabular}

weight of the sample at time $t$, and $w_{0}$ is the total oxygen content.

\subsection{Reduction Apparatus and Procedure}

\subsubsection{Reduction System and Procedure}

Thermogravimetry (TG) was used to measure both isothermal and non-isothermal reactions. The reduction apparatus is illustrated in Fig. 3. The main parts of the reduction system include a vertical tube furnace $(\mathrm{F})$, fitting with an alumina reaction tube (A) and an automatic sensitive balance (B) at the top. The data from the balance $(\mathrm{O})$ is connected to a recording unit (R) for continuous monitoring of the weight loss of samples during the experiments. The control parts $(\mathrm{K})$ are two thermocouples T1 and T2. The temperatures of the furnace and sample are measured with two different thermocouples, one in the hot zone (T1) and the other behind the sample (T2). A gas supply system and gas purification unit (E) is used to remove moisture and other contaminants from the gases.

\subsubsection{Isothermal Experimental Procedure}

In experiments, the furnace is heated up to a target temperature and maintained at this temperature for around $5 \mathrm{~min}$. Pure argon (Ar) gas is then introduced into the furnace at a flow rate of $1.0 \mathrm{l} / \mathrm{min}$. After that, the sample is placed in a basket which hangs from the balance arm by a wire; then, the basket is positioned in the hot zone of the furnace. Under these conditions, Ar gas is replaced by $1.0 \mathrm{l} / \mathrm{min}$ of $\mathrm{H}_{2}$. During the experiment, the weight loss of the sample due to $\mathrm{O}_{2}$ removal is continuously recorded until the weight remains constant. At the end of the experiment, $\mathrm{H}_{2}$ gas is replaced by Ar gas and the furnace is cooled back down to room temperature. The reduced sample is taken out and kept in a desiccator for later characterization.

\subsubsection{Non-Isothermal Experimental Procedure}

In these tests, the furnace is first flushed with Ar at a flow rate of $0.2 \mathrm{l} / \mathrm{min}$ and held in this condition for $5 \mathrm{~min}$. Then, the Ar gas switched to $\mathrm{H}_{2}$, which introduced at a flow rate of 1.0 $1 / \mathrm{min}$. The sample is heated in the reducing gas from room temperature to $1000{ }^{\circ} \mathrm{C}$ at different heating rates $(5,10,15$, and $20{ }^{\circ} \mathrm{C} / \mathrm{min}$ ). At the end of the experiment, the $\mathrm{H}_{2}$ is replaced by Ar gas and the furnace is cooled back down to room temperature. The reduced sample is taken out and kept in a desiccator for later characterization.

\section{Results and Discussion}

\subsection{Isothermal Reduction}

\subsubsection{Reduction Behavior}

The reduction curves of $\mathrm{Fe}_{2} \mathrm{O}_{3}$ compacts by $\mathrm{H}_{2}$ gas at temperatures 800 to $1100{ }^{\circ} \mathrm{C}$ are illustrated in Fig. 4. For any given reduction temperature, the rate of reduction is highest in the early stages and gradually decreases until the end of the reduction reaction. At low temperatures, the reduction takes longer and the reduction time decreases as reduction
Fig. 2 Photomicrographs of iron ore sample. a SEM $(\times 5000)$. b $\operatorname{RLM}(\times 100)$
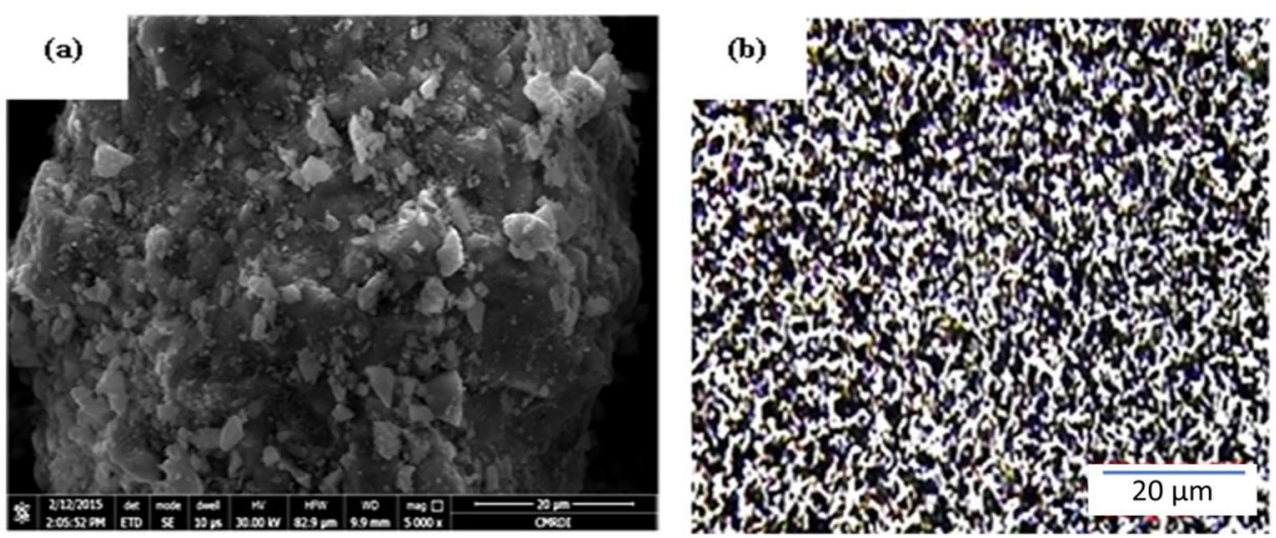
Fig. 3 Schematic diagram for reduction apparatus of TGA system

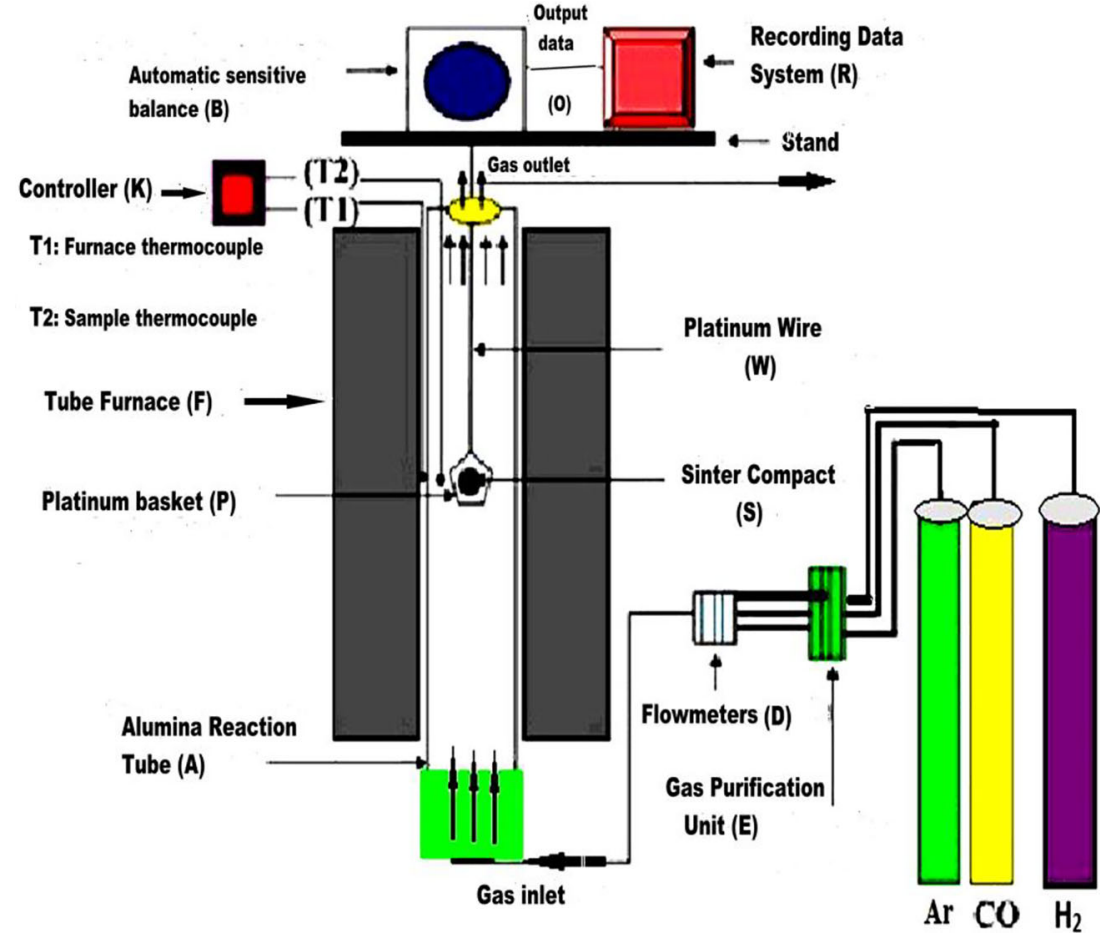

temperature increases. Furthermore, the extent of reduction at the maximum values (the plateau) appears to increase with rise in temperatures. The high degree of reduction during the initial and intermediate stages can be attributed to the reduction of $\mathrm{Fe}_{2} \mathrm{O}_{3}$ to $\mathrm{Fe}_{3} \mathrm{O}_{4}$ and from $\mathrm{Fe}_{3} \mathrm{O}_{4}$ to $\mathrm{Fe}$. The relatively slowing down of the reduction rate during the final stages is caused by the reduction of $\mathrm{FeO}$ to $\mathrm{Fe}$.

In the case of reduction using $\mathrm{CO}$ at temperatures 80--900 ${ }^{\circ} \mathrm{C}$, samples did not complete reduction and stopped at different extents of reduction, depending on the applied temperature [26]. Moreover, during experiments, an increase in the weight of the compacts was observed. This phenomenon previously observed elsewhere [27] indicates that the rate of carbon participation as a result of the thermal decomposition of carbon monoxide $\left(2 \mathrm{CO}=\mathrm{C}+\mathrm{CO}_{2}\right)$ is greater than the rate of oxygen removal.

The microstructure of the completely reduced compacts with $\mathrm{H}_{2}$ at 950 and $1100{ }^{\circ} \mathrm{C}$ is given in Fig. 5a and b, respectively. Figure $5 \mathrm{a}$ illustrates that the structure includes elongated grains of metallic iron and coalesces to each other with separated small macropores. As the reduction temperature increases, the matrix structure became relatively dense due to the coalescence and connection of metallic grains as shown in Fig. $5 b$.

\subsubsection{Kinetics and Mechanism of Iron Ore Reduction}

According to previous literature [12], iron ore reduction is supposed to take place from the surface and progress to the
Fig. 4 Reduction behaviors of iron ore compacts at $800-1100{ }^{\circ} \mathrm{C}$ by pure $\mathrm{H}_{2}$

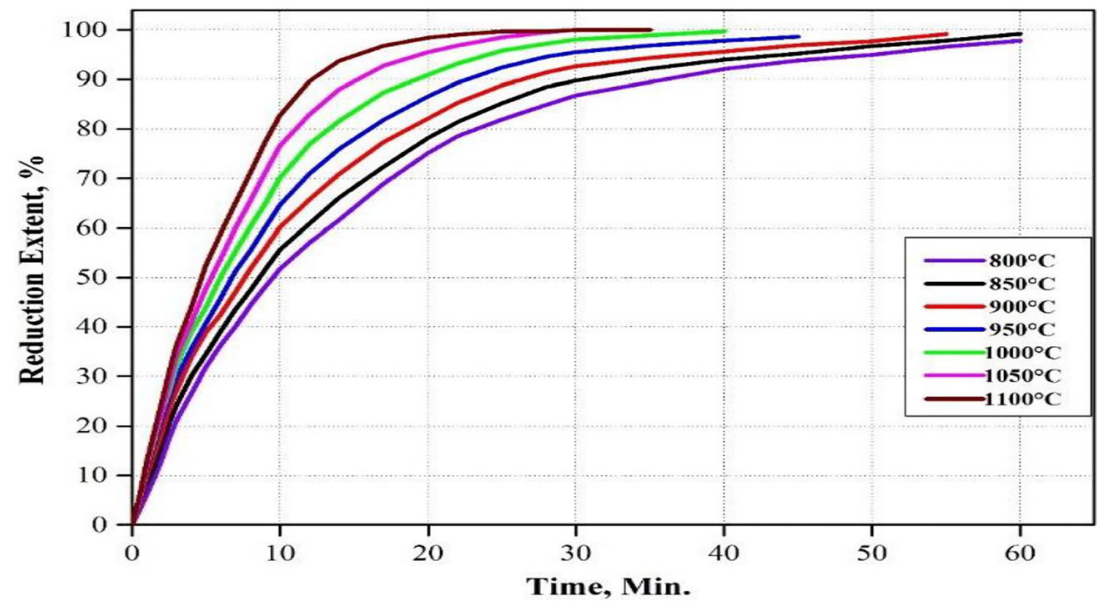


Fig. 5 RLM photomicrograph of $\mathrm{Fe}_{2} \mathrm{O}_{3}$ compact $100 \%$ reduced by $\mathrm{H}_{2}$ at $950\left(\right.$ a) and $1100{ }^{\circ} \mathrm{C}(\mathbf{b})$ with $\times 500$
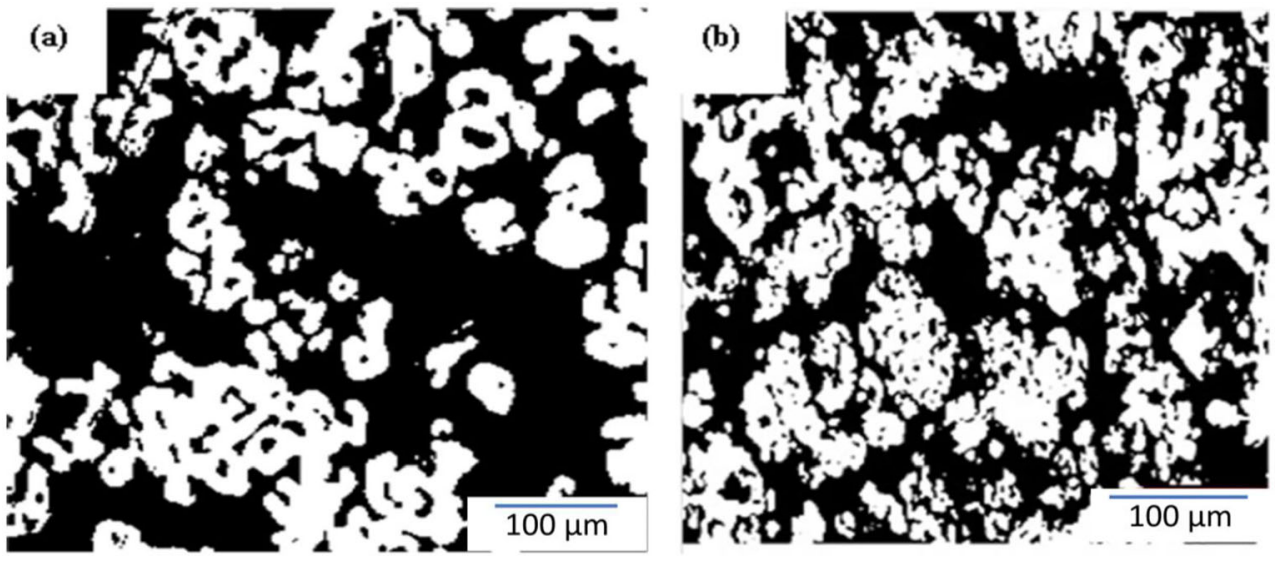

core and the diameter of the unreacted core becomes smaller and smaller until zero. The reduction mechanisms of iron ore during both the initial and final stages can be deduced from the correlations between the apparent activation energy values, the gas-solid chemical reaction, and the microstructure of the reduced samples in the reduction procedure [26, 28-31]. The kinetics of iron ore reduction can be described using a shrinking unreacted core model to elucidate the reduction reaction. In the beginning, iron ore particles are assumed to have $100 \%$ hematite and have an initial diameter. With the increase in the reduction reaction, a product layer of iron is created and the unreacted core of pellet particle is decreased to a smaller diameter. A layer of reactant gas exists at the initial diameter of the iron ore particle. A chemical reduction reaction can be divided into three stages: external diffusion, internal diffusion, and chemical reaction. The chemical reaction is expressed by the Arrhenius equation in Eq. 3:

$K_{\mathrm{r}}=K_{\mathrm{o}} e^{-E a / R T}$

where $K_{\mathrm{r}}$ is the reaction rate constant, $K_{\mathrm{o}}$ is the frequency factor, $E a$ is the apparent activation energy, $R$ is the gas constant, and $T$ is the absolute temperature.

The rate of reaction $(K)$ is calculated using the isothermal curves given in Fig. 4. The relationships between $\operatorname{lnK}$ and $(1 / T)$ are plotted during both the initial stages $(5-15 \%)$ and the final stages of reduction (85-95\%) as shown in Fig. 6. The computed apparent activation energy values for the reduction

Table 3 Apparent $E a$ values calculated at the initial and final stages of reduction

\begin{tabular}{lll}
\hline \multirow{2}{*}{ Reducer of $\mathrm{Fe}_{2} \mathrm{O}_{3}$ compacts } & \multicolumn{2}{l}{$E a$ values (kJ/mole) } \\
\cline { 2 - 3 } & At 5-10\% extents & At 85-95\% extents \\
\hline $\mathrm{H}_{2}$ & 28.34 & 41.15 \\
$\mathrm{CO}$ & 39.23 & $54.19[26]$ \\
\hline
\end{tabular}

by $\mathrm{H}_{2}$ and $\mathrm{CO}$ are listed in Table 3 . The comparison of activation energy values indicated that reduction with $\mathrm{H}_{2}$ is more efficient than with CO.

At the initial stages, the Ea value indicates that the reduction process seems to be controlled by a mixed mechanism of gaseous diffusion and interfacial chemical reaction. During the final stages, the Ea value reveals that the reaction is controlled by interfacial chemical reaction and this matched with other studies [17, 26, 32].

The mathematical models that are typically adopted for predicting kinetics mechanisms in heterogeneous gas-solid reactions and the grain model developed by Szekely et al. [28] are the most accurate one for the similar experimental conditions, in which long cylinder samples are produced from compacting fines of solid materials. Gaseous diffusion, interfacial chemical reaction, and mixed control mathematical formulae have been tested in this study to evaluate the control stage in the overall reduction process. The three mathematical kinetic equations are as follows [28, 32]:

(a) For gaseous diffusion mechanism:

$K=X+(1-X) \ln (1-X)$

(b) For chemical reaction mechanism:

$K=1-(1-X)^{0.5}$

(c) For mixed control mechanism:

$K=1-(1-X)^{0.5}+X+(1-X) \ln (1-X)$

where $K$ and $X$ express the rate of reaction and the fractional reduction degree, respectively.

In order to confirm the reduction mechanism prediction from the activation energy values, the above chemical reaction 
Fig. 6 Arrhenius plots for $\mathrm{Fe}_{2} \mathrm{O}_{3}$ compacts reduced by $\mathrm{H}_{2}$

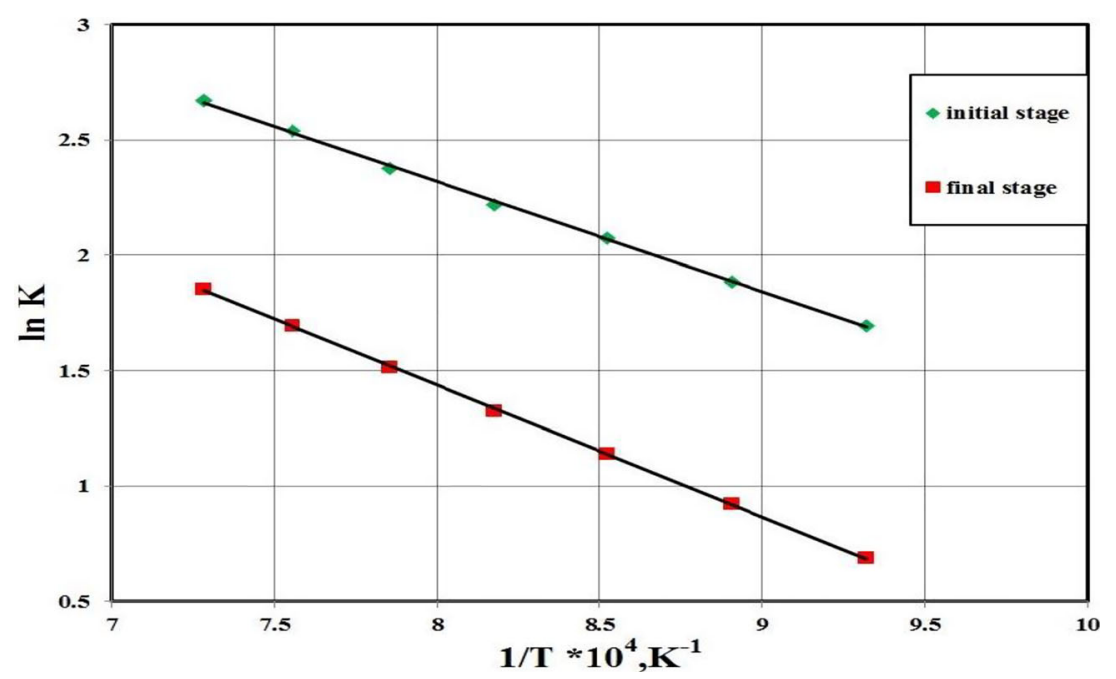

formulations were tested against experimental results as presented in Figs. 7 and 8. During the initial stages, linear correlations were provided from the application of the mixed control mechanism (Eq. 6) as shown in Fig. 7. During the final stages, linear correlations were obtained when applying an interfacial chemical reaction (Eq. 5) as illustrated in Fig. 8. These are consistent with the mechanisms suggested by the activation energy values.

The morphological structures of the reduced samples at $1000{ }^{\circ} \mathrm{C}$ during the initial and final stages are shown in Fig. $9 \mathrm{a}, \mathrm{b}, \mathrm{c}, \mathrm{d}$, respectively. Figure 9 a shows the formation of a relatively porous structure which facilitates the access of gas diffusion. Figure $9 b$ shows the formation of the outer/middle interface (red line) of the compact, which is comprised of ironwustite phase diffusion in the wustite matrix. This indicates that the reducing gas is easily diffused through the outer shell and consequently, iron is nucleated and grows up on the surface of the wustite particles allowing the development of the iron-wustite intergrowth layer. Resistance to gas diffusion decreases near the surface of wustite grains and the chemical reaction resistance has a major effect as a controlling mechanism. Therefore, mixed mechanism combines gas diffusion and interfacial chemical reaction controlling the reaction. Figure 9c illustrates that the grains of metallic iron are coalescing to each other with small separate macropores. As the reduction proceeds, large macropores are observed due to the coalescing of metallic iron grains as shown Fig. 9d. Accordingly, gas diffusion becomes easier through relatively porous structures, so the reaction is controlled by chemical reaction mechanism.

\subsection{Non-Isothermal Reduction}

\subsubsection{Reduction Behavior}

Non-isothermal experiments were carried out at temperatures ranging from room temperature up to $1000{ }^{\circ} \mathrm{C}$ in $\mathrm{H}_{2}$ atmosphere using different heating rates $\left(5,10,15\right.$, and $\left.20^{\circ} \mathrm{C} / \mathrm{min}\right)$. The results are shown in Fig. 10. The heating rate has a considerable effect on the reduction process. The degree of
Fig. 7 Application of mathematical equation at the initial stages of reduction (5$15 \%)$

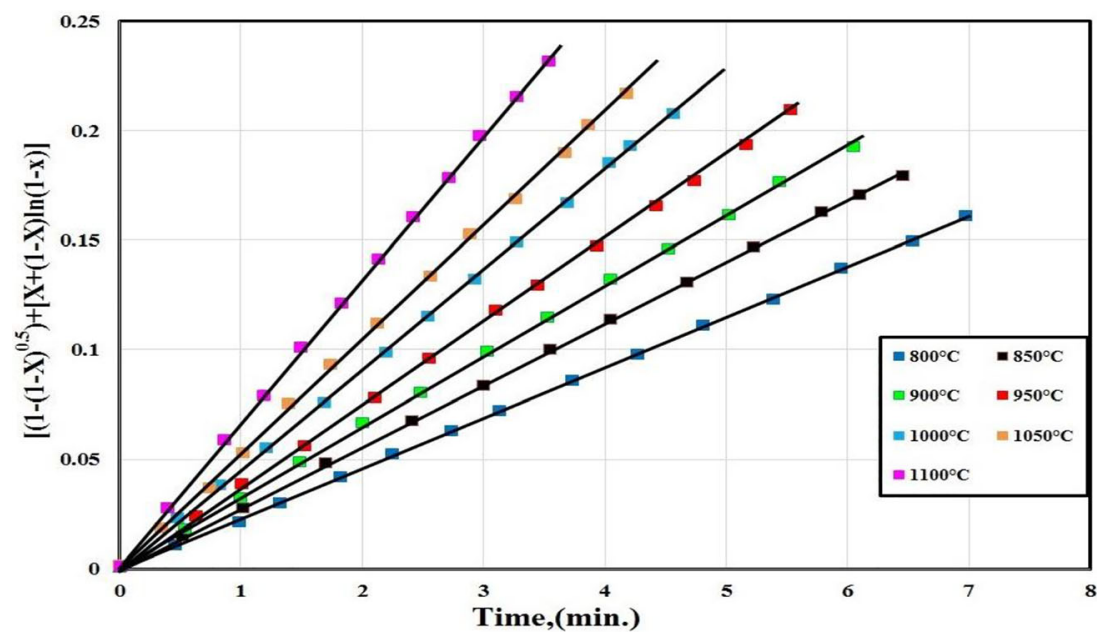


Fig. 8 Application of

mathematical equation at the final

stages of reduction (85-95\%)

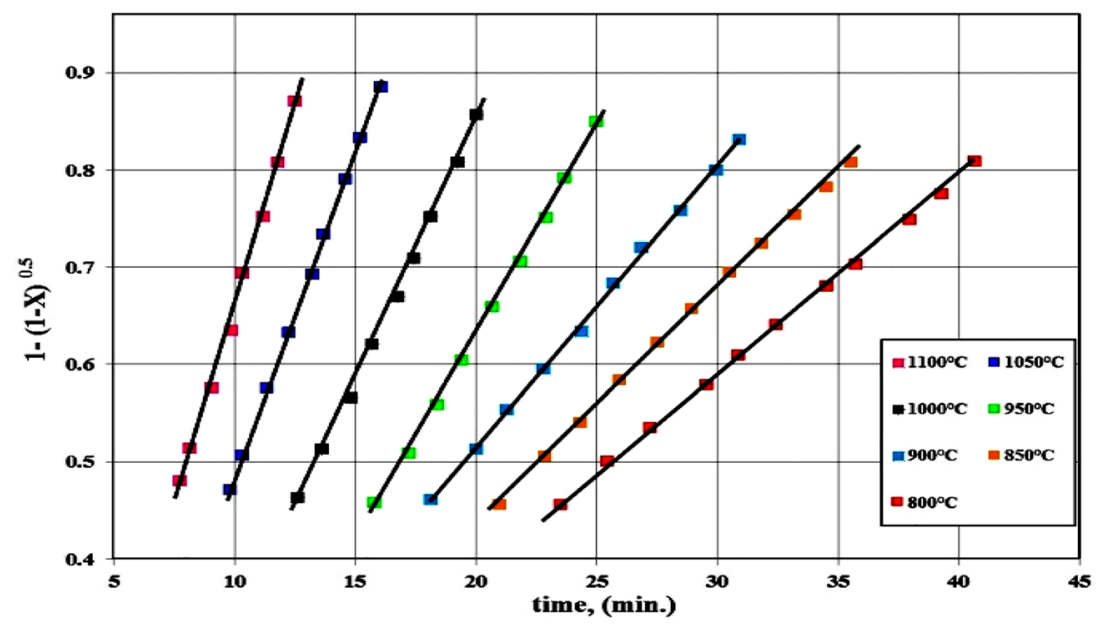

reduction decreases as the heating rate increases. Increasing heating rates leads to shorter time for the sample at any particular temperature. At the same heating rate, the degree of reduction is higher in $\mathrm{H}_{2}$ than in $\mathrm{CO}$ atmosphere [26].

For any given reduction curve presented in Fig. 10, the reduction process can be categorized into three steps:

i. Incubation step, from the beginning up to $\approx 400{ }^{\circ} \mathrm{C}$, during which no reduction reaction occurs.

ii. Induction step, from temperature $>400$ up to $800{ }^{\circ} \mathrm{C}$, where the reduction rate greatly increases with the rise in temperature and depending on the applied heating rate.

iii. Deceleration step, over $800{ }^{\circ} \mathrm{C}$, at which the reduction rate decreases until the end of experiment.

\subsubsection{Kinetics and Mechanism}

There are many methods available for evaluating nonisothermal kinetic parameters [33, 34]. This study employs two mathematical analysis methods to determine the kinetic parameters: a model-free isoconversional analysis and model fitting $[35,36]$.

The overall reaction rate can be generally described by [34]

$\frac{d \alpha}{d t}=A \exp \left(\frac{-E a}{R t}\right) f(\alpha)$

Under non-isothermal condition, when the sample is heated at a constant heating rate, the explicit temporal in Eq. 7 is eliminated through the trivial transformation
Fig. 9 RLM photomicrograph $(x$ 500) of $\mathrm{Fe}_{2} \mathrm{O}_{3}$ reduced by $\mathrm{H}_{2}$ at $1000{ }^{\circ} \mathrm{C}$. a, b $15 \%$ reduction extent at the initial stage. c, d $85 \%$ reduction extent at the final stage
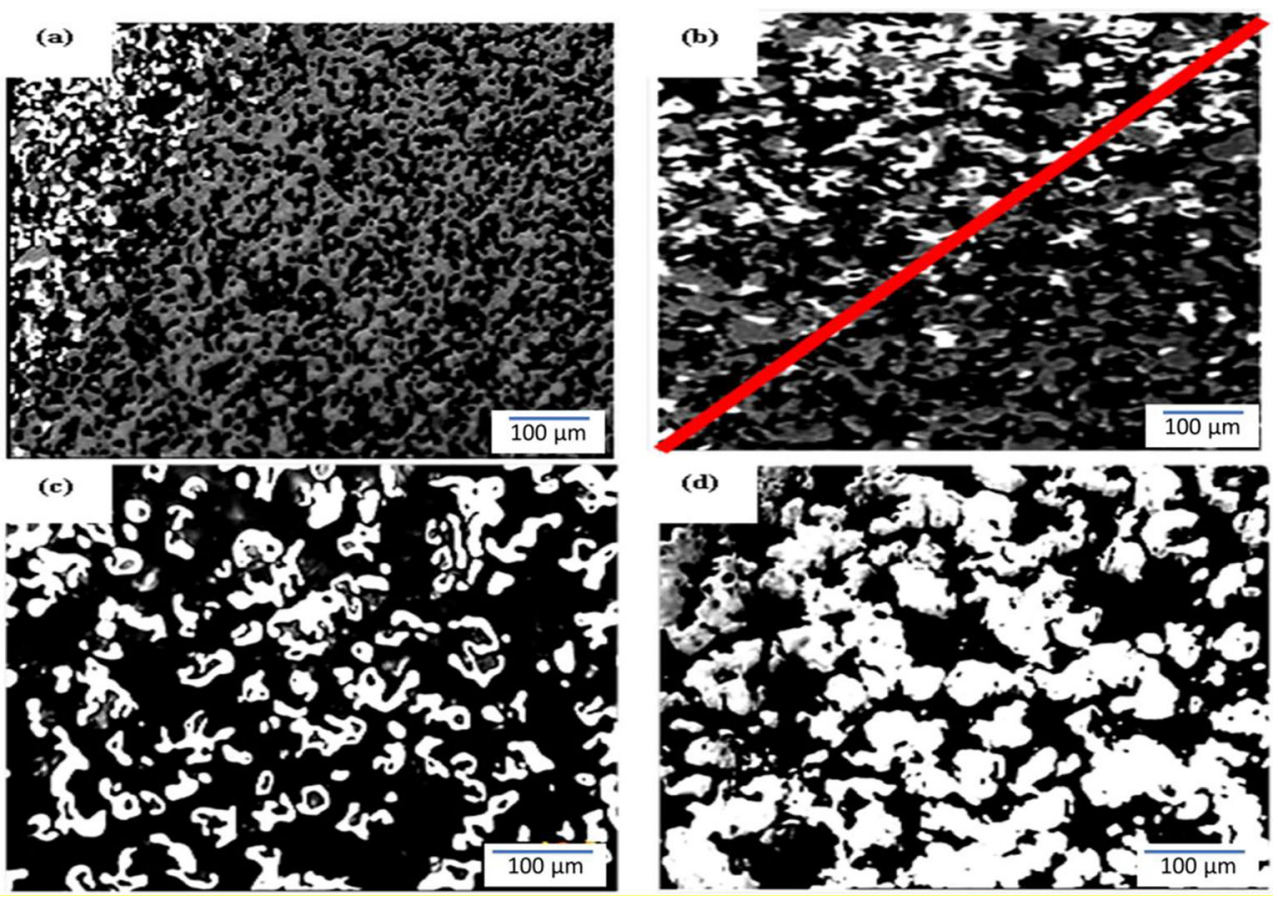
Fig. 10 Effect of heating rates on reduction extent of $\mathrm{H}_{2}$ reaction

$\frac{d \alpha}{d T}=\frac{d \alpha}{d t} * \frac{d t}{d T}=\frac{A}{\beta} \exp \left(\frac{-E a}{R T}\right) f(\alpha)$

where $\beta$ is the heating rate. Upon integration, Eq. (8) gives

$g(a)=\int_{0}^{a} \frac{d(a)}{f(a)}=\frac{A}{\beta} \int_{0}^{T} \exp \left(\frac{-E a}{R T}\right) d T$

Model-free isoconversional methods estimate the kinetic parameters without modelistic assumptions [35-37]. The basic assumption of this method is that the reaction rate at a given conversion degree is only a function of temperature [38]. A typical example of this kind of approach is the Kissinger-Akahira-Sunose (KAS Eq. 10) method, which has been widely used to analyze the reaction of kinetic parameters as a function of the conversion degree.

$\ln \frac{\beta}{T^{2}}=\ln \left(\frac{A E a}{g(\alpha) R}\right)-\frac{E a}{R T}$

Figure 11 shows the KAS plots of $\ln \beta / T^{2}$ against $1 / T$ for different conversion degree values. The apparent activation energy values listed in Table 4 were computed using the slopes of the lines drawn. With the increase in reduction during the process, the $E a$ value becomes smaller and smaller from 92.57 to 20.19 .

In order to predict the most probable reduction mechanism, model-fitting methods were employed. The model offering the best statistical fit was chosen as the reaction model that was used to determine the kinetic parameters. Coats and Redfern (CR) have provided one of the most popular modelfitting methods [39].

$\ln \frac{g(a)}{T^{2}}=\ln \left(\frac{A R}{\beta E a}\left[1-\left(\frac{2 R T_{\exp }}{E a}\right)\right]\right)-\frac{E a}{R T}$

where $T$ is the mean experimental temperature and $g(a)$ is a function that mathematically describes the reaction kinetics.

Several models tabulated elsewhere [40] for the integral form $g(\alpha)$ were tested according to CR method. The plot of $\ln \left[g(\alpha) / T^{2}\right]$ versus $1 / T$ will be linear with a high correlation coefficient. Figure 12 reveals that the Avrami-Erofeev model provides a linear trend with a correlation coefficient $(R)$ higher than 0.99 , indicating that the reduction is controlled by the Avrami-Erofeev model.

The calculated activation energy values $(E a)$ at different conversion degrees $(\alpha)$ are presented in Fig. 13. Higher activation energy values were obtained at earlier stages and decrease as the reduction extents increased. The reduction starts at a lower temperature and requires high energy ( $E a)$ to proceed. The decreasing in $E a$ values can be attributed to the effect of temperature, which has a considerable effect on the reduction process.

The morphological changes in the completely reduced samples at $20^{\circ} \mathrm{C} / \mathrm{min}$ and $5{ }^{\circ} \mathrm{C} / \mathrm{min}$ analyzed using an SEM microscope are shown in Fig. 14a and b, respectively. Figure 14a illustrates that the microstructure of iron ore includes significant porosity and the formation of metallic iron whiskers. Furthermore, the formation of dense structures of
Table 4 Apparent activation energy values computed at overall reduction reaction

\begin{tabular}{lllllllllll}
\hline $\begin{array}{l}\text { Conversion } \\
\text { degree }(\alpha)\end{array}$ & 0.1 & 0.2 & 0.3 & 0.4 & 0.5 & 0.6 & 0.7 & 0.8 & 0.9 & 1 \\
\hline Ea value & 92.57 & 79.34 & 66.71 & 56.89 & 45.21 & 38.97 & 33.96 & 30.03 & 25.61 & 20.19 \\
\hline
\end{tabular}


Fig. 11 Kissinger plot at different reduction extents of $\mathrm{Fe}_{2} \mathrm{O}_{3}$ reduced by $\mathrm{H}_{2}$

Fig. 12 Coats-Redfern plot of reduction of iron ore compacts with $\mathrm{H}_{2}$ gas

Fig. 13 Calculation $E a$ against conversion degree of iron ore compact reduced by $\mathrm{H}_{2}$
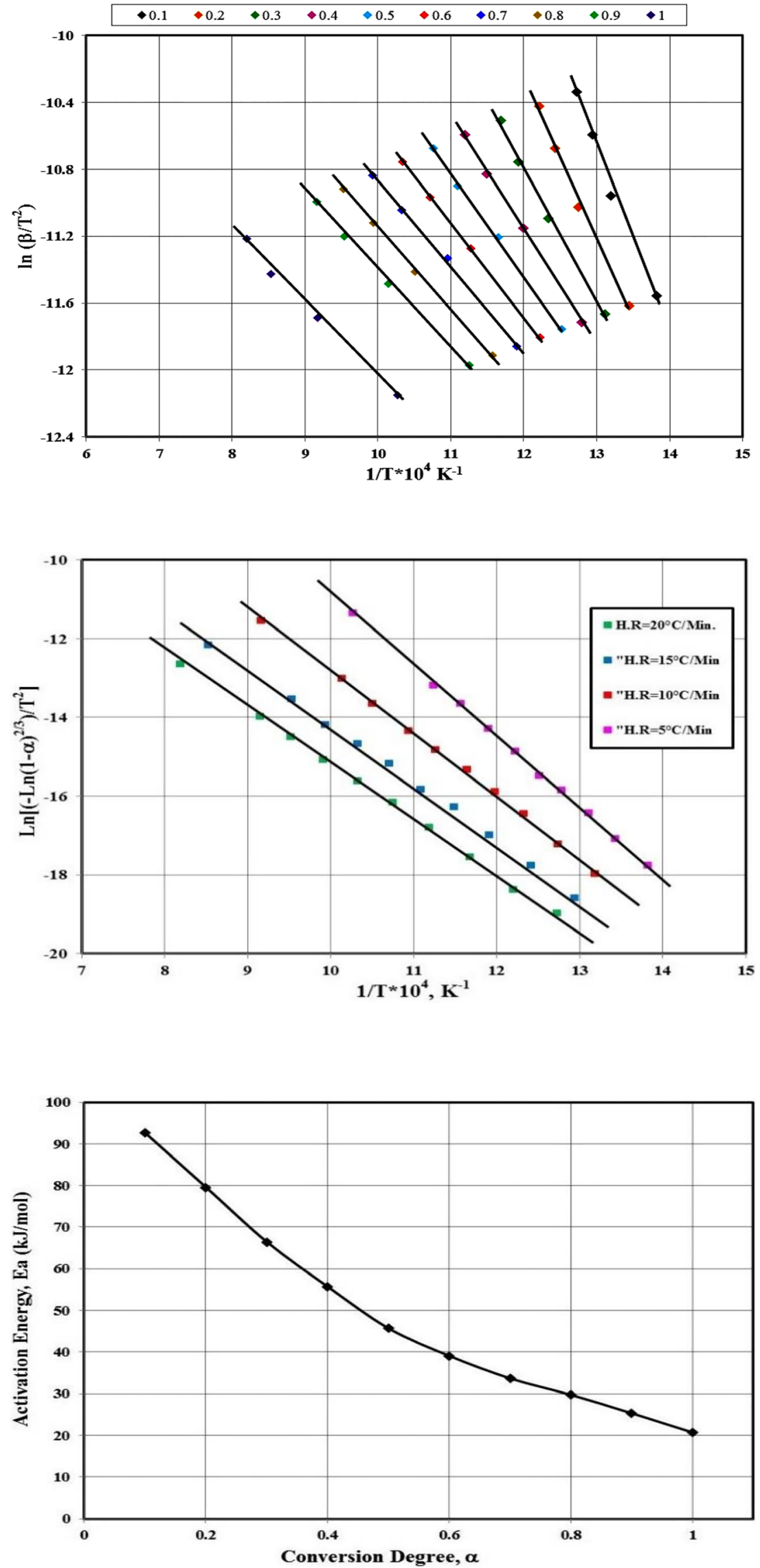
Fig. 14 SEM images of iron oxide fines non-isothermally reduced with $\mathrm{H}_{2}$ up to $1000{ }^{\circ} \mathrm{C}$. a $\mathrm{HR}=20^{\circ} \mathrm{C} / \mathrm{min}$. b HR $=5$

${ }^{\circ} \mathrm{C} / \mathrm{min}$

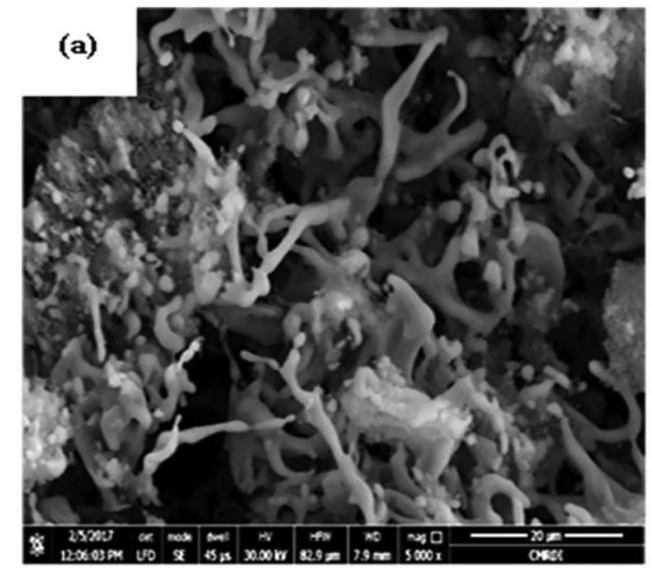

metallic iron grain results from the connections between the metallic iron grains as shown in Fig. 14b.

The microstructure of fully reduced samples at different heating rates $\left(20,15,10\right.$, and $\left.5{ }^{\circ} \mathrm{C} / \mathrm{min}\right)$ examined by a reflected light microscope is presented in Fig. 15a-d. It can be observed that the heating rate has an obvious effect on the structure of the iron grains. Figure $15 \mathrm{a}\left(20^{\circ} \mathrm{C} / \mathrm{min}\right)$ shows a structure that includes bright white grains of metallic iron scattering all over the matrix. Figure $15 \mathrm{~b}\left(15^{\circ} \mathrm{C} / \mathrm{min}\right)$ illustrates that the grains of metallic iron connected together forming a relatively dense matrix with small separate macropores. By decreasing the heating rate as shown in Fig. $15 \mathrm{c}\left(10^{\circ} \mathrm{C} / \mathrm{min}\right)$, the matrix includes large grains of metallic iron which contain micropores. As shown in Fig. 15d (5 ${ }^{\circ} \mathrm{C} / \mathrm{min}$ ), denser structure can be observed attributable to sintering and the connection of metallic iron grains. These above results indicate that the microstructure of samples becomes denser as the heating rate decreases. This is most likely attributable to the relatively longer reaction time, which allows more time for growth of the metallic iron grains.

Figure 16 shows the XRD patterns of non-isothermal reduction products at different heating rates and at $1000^{\circ} \mathrm{C}$. The intensity of the metallic iron peaks increases as heating rates decrease, because of the longer retention time of the sample, and consequently enhances the recrystallization of the iron phase, which is evident from Fig. 15.
Fig. 15 RLM photomicrograph of iron ore fines non-isothermally reduced at $1000{ }^{\circ} \mathrm{C}(\times 500)$. a 20 ${ }^{\circ} \mathrm{C} / \mathrm{min}$. b $15^{\circ} \mathrm{C} / \mathrm{min}$. c 10 ${ }^{\circ} \mathrm{C} / \min$. d $5{ }^{\circ} \mathrm{C} / \min$
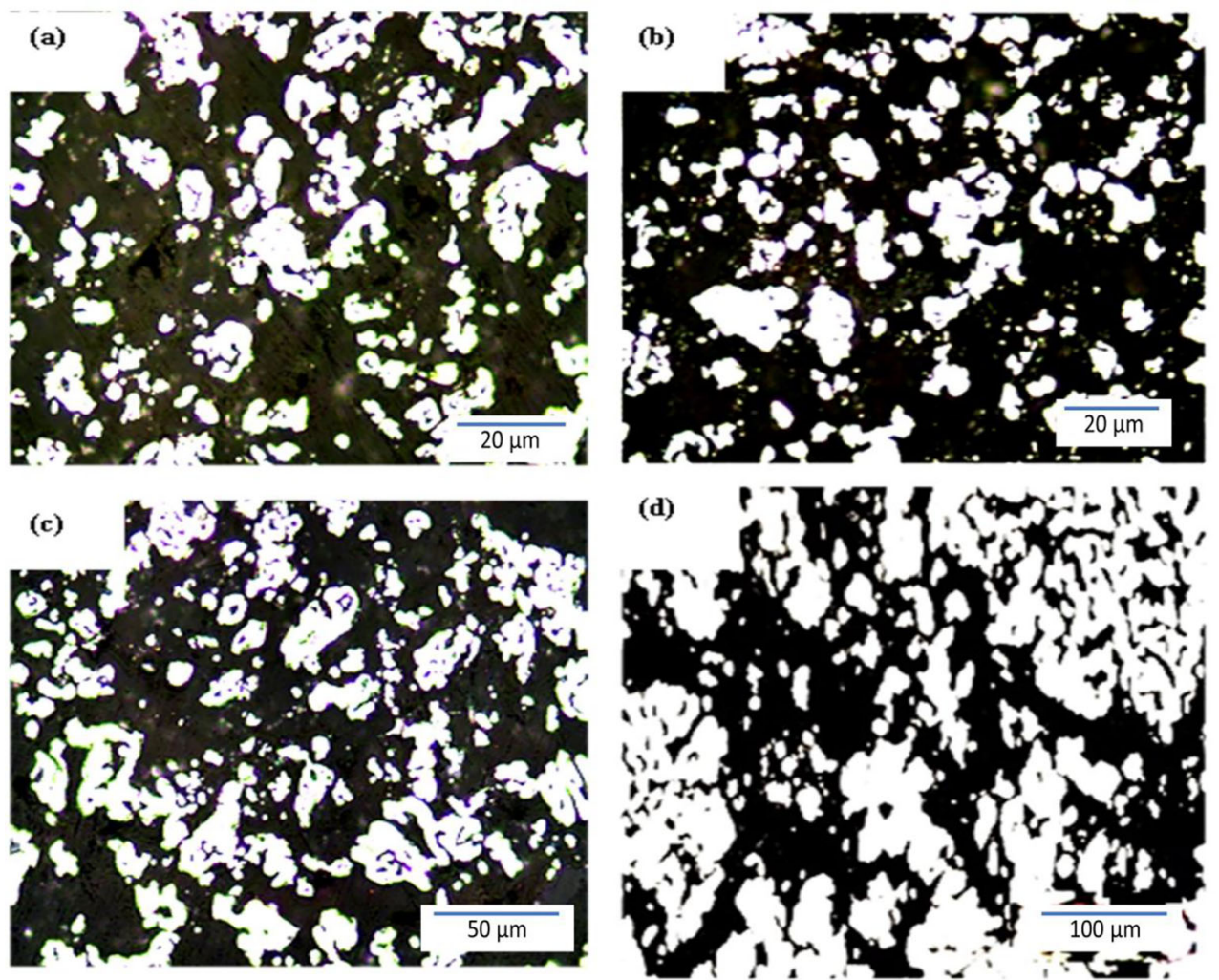
Fig. $16 \mathrm{XRD}$ patterns of the samples reduced by $\mathrm{H}_{2}$ at four heating rates

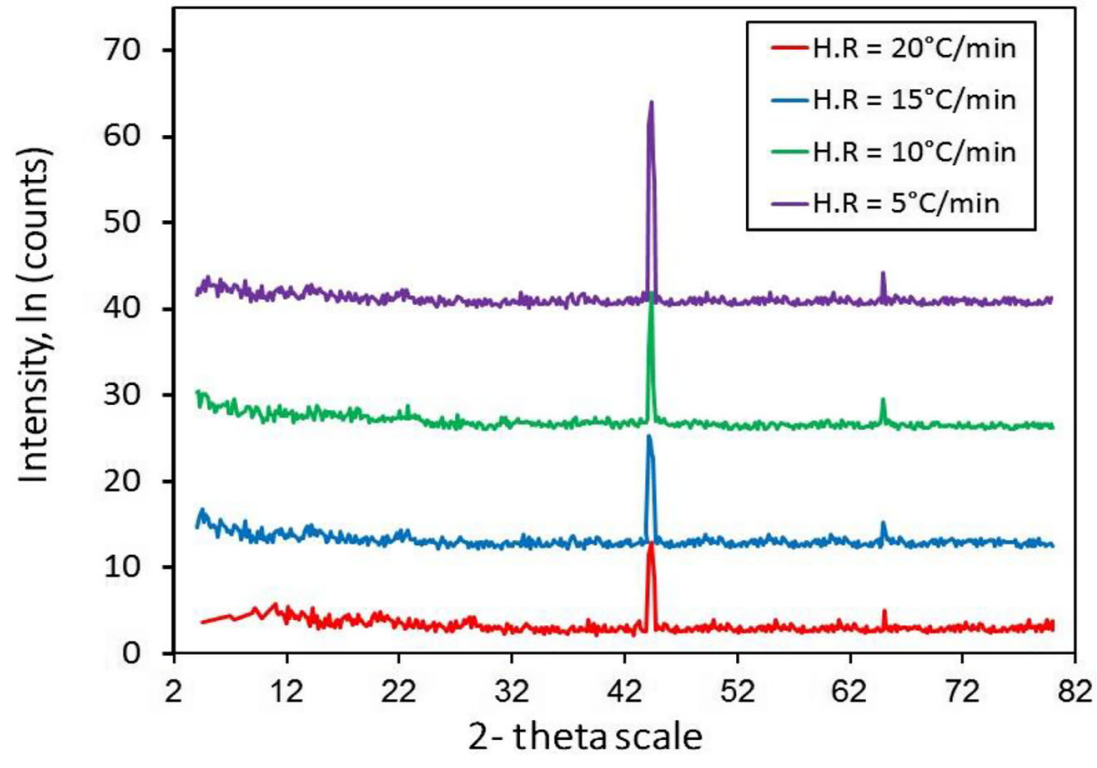

\section{Conclusion}

Understanding the kinetic analysis of non-isothermal conditions is helpful in the DR process and in hydrogen metallurgy. The latter has become important topic in the global steel industry and in academic fields in recent years. It provides promising solution that could be very effective in decreasing the $\mathrm{CO}_{2}$ emissions and also metallurgical coke utilization in iron and steel industry by optimization of hydrogen-rich materials such as natural gas in the ironmaking processes. Such solutions require intensive investigations in order to understand and precisely evaluate their influence on iron and steel industry and $\mathrm{CO}_{2}$ mitigation. This study investigated isothermal and non-isothermal reductions of iron ore fines in a pure $\mathrm{H}_{2}$ atmosphere. In the experiments, total weight loss was continuously recorded using TG and the kinetic mechanisms were studied. The experimental results and kinetic analyses suggest the following conclusions:

1. Temperature plays a significant role in the isothermal reduction process. The reduction rate during the initial stages is higher than the reduction rate during the final stages.

2. The rate-controlling mechanism of the reduction process was predicted using an activation energy calculation, through applying gas-solid mathematical models, and microstructure examination. During the initial stages, the reduction reaction was controlled by a mixed mechanism of interfacial chemical reaction and gas diffusion. During the final stages, the interfacial chemical reaction was the rate-determining step.

3. The heating rate has a significant effect on the reduction rate and reduction conversion for non-isothermal reductions. With identical heating rates, the degree of reduction was higher in $\mathrm{H}_{2}$ than in $\mathrm{CO}$ atmosphere.

4. The kinetic mechanisms of the reductions could be predicted by applying model-free and model-fitting methods. The wide range of activation energy values (92.57 to 20.19 ) in the model-free approach was mainly a result of temperature differences. When applying the CoatsRedfern method, the reduction reaction was controlled by the Avrami-Erofeev model.

Funding Open access funding provided by University of Oulu including Oulu University Hospital. Thus study was financially supported by The Program for Professor of Special Appointment (Eastern Scholar) at Shanghai Institutions of Higher Learning (No. TP2015039), National Natural Science Foundation of China (No. 51974182), National 111 project, Grant/Award No. 17002, and CSC support for Ph.D. from the Belt and Road Countries.

\section{Compliance with Ethical Standards}

Conflict of Interest The authors declare that they have no conflict of interest.

Open Access This article is licensed under a Creative Commons Attribution 4.0 International License, which permits use, sharing, adaptation, distribution and reproduction in any medium or format, as long as you give appropriate credit to the original author(s) and the source, provide a link to the Creative Commons licence, and indicate if changes were made. The images or other third party material in this article are included in the article's Creative Commons licence, unless indicated otherwise in a credit line to the material. If material is not included in the article's Creative Commons licence and your intended use is not permitted by statutory regulation or exceeds the permitted use, you will need to obtain permission directly from the copyright holder. To view a copy of this licence, visit http://creativecommons.org/licenses/by/4.0/. 


\section{References}

1. Pardo N, Moya JA (2013) Prospective scenarios on energy efficiency and $\mathrm{CO}_{2}$ emissions in the European Iron \& Steel industry. Energy 54:113-128

2. Mousa E, Wang C, Riesbeck J, Larsson M (2016) Biomass application in iron and steel industry: an overview of challenges and opportunities. Renew Sustain Energy 65:1247-1266

3. World Steel Association (2018) Steel Statistical Yearbook 2018, vol 20. World Steel Association, Brussels

4. Ahmed H (2018) New trends in the application of carbon-bearing materials in blast furnace ironmaking. Minerals 8(12):561

5. International Energy Agency (2010) Energy technology perspectives: scenarios and strategies to 2050, Paris, France.

6. Wang $\mathrm{X}$, Lin $\mathrm{B}$ (2016) How to reduce $\mathrm{CO}_{2}$ emissions in China's iron and steel industry. Renew Sust Energ Rev 57:1496-1505

7. Wright JK, Taylor I, Philp DK (1991) A review of progress of the development of new ironmaking technologies. Miner Eng 47:9831001

8. Olsson, O (2018) Low-emission steel production: decarbonising heavy industry. Available online: https://www.sei.org/ perspectives/low-emission-steel-production-hybrit (accessed on 11 April 2018).

9. Quailan H (2019) Hydrogen as a clean alternative in the iron and steel industry. http://www.fchea.org/in-transition/2019/11/25/ hydrogen-in-the-iron-and-steelindustry.

10. Pasquale $\mathrm{C}$ (2019) Clean ironmaking and steelmaking processes efficient technologies for greenhouse emissions abatement.

11. Abdelrahim A, Iljana M, Omran M, Vuolio T, Bartusch H, Fabritius $\mathrm{T}$ (2020) Influence of $\mathrm{H}_{2}-\mathrm{H}_{2} \mathrm{O}$ content on the reduction of acid iron ore pellets in a CO-CO $\mathrm{CO}_{2}-\mathrm{N}_{2}$ reducing atmosphere. ISIJ Int. https:// doi.org/10.2355/isijinternational.ISIJINT-2019

12. Spreitzer D, Schenk J (2019) Reduction of iron oxides with hydrogen-a review. Steel Res Int 90:1900108. https://doi.org/10. 1002/srin.201900108

13. El-Geassy AA, Shehat KA, Ezz SY (1977) Mechanism of iron oxide reduction with hydrogen/carbon monoxide mixtures. Trans ISIJ 17:629

14. El-Geassy AA (1999) Influence of doping with $\mathrm{CaO}$ and/or $\mathrm{MgO}$ on stepwise reduction of pure hematite compacts. Ironmak Steelmak 26(1):41

15. El-Geassy AA, Nasr MI, Hessein MM (1996) Effect of reducing gas on the volume change during reduction of iron oxide compacts. ISIJ Int 36:640

16. Nasr MI, Omar AA, Hessein MM, El-Geassy AA (1996) Carbon monoxide reduction and accompanying swelling of iron oxide compacts. ISIJ Int 36(2):164

17. Strangway PK (1964) Kinetics of reduction of iron oxide by reformed natural gas. M.Sc. Thesis, Metallurgy and Materials Science, Toronto University.

18. Spreitzer D, Schenk J (2019) Iron ore reduction by hydrogen using a laboratory scale fluidized bed reactor: kinetic investigationexperimental setup and method for determination. Metall Mater Trans A 50B:2471

19. Lin HY, Chen YW, Li C (2003) The mechanism of reduction of iron oxide by hydrogen. Thermochim Acta 400:6

20. Piotrowski K, Mondal K, Lorethova H, Stonawski L, Szymanski T, Wiltowski T (2005) Effect of gas composition on the kinetics of iron oxide reduction in a hydrogen production process. Int $\mathrm{J}$ Hydrog Energy 30(15):1543-1554
21. Bonalde A, Henriquez A, Manrique M (2005) Kinetic analysis of the iron oxide reduction using hydrogen/carbon monoxide mixtures as reducing agent. ISIJ Int 45(9):1255-1260

22. Skorianz M (2012) Ph.D. Thesis, Montan University Leoben.

23. GeonYong L, Song J, JaiSung L (2016) Reaction kinetics and phase transformation during hydrogen reduction of spherical $\mathrm{Fe}_{2} \mathrm{O}_{3}$ nanopowder agglomerates. Powder Technol 302:215-221

24. Dang J, Guohua Z, Xiaojun H, Kuochih C (2013) Non-isothermal reduction kinetics of titanomagnetite by hydrogen. Int $\mathrm{J}$ Miner Metall Mater 20:1134

25. Tiernan MJ, Barnes PA, Parkes GM (2001) Reduction of iron oxide catalysts: the investigation of kinetic parameters using rate perturbation and linear heating thermoanalytical techniques. J Phys Chem 105B:220-228

26. El-Geassy AA, Nasr MI, El-Raghy SM, Hammam AA (2019) Comparative studies on isothermal and non-isothermal reduction of hematite in carbon monoxide atmosphere. Ironmak Steelmak. https://doi.org/10.1080/03019233.2019.1646564

27. EI-Geassy AA (1986) Gaseous reduction of $\mathrm{Fe}_{2} \mathrm{O}_{3}$ compacts at 600 to $1050{ }^{\circ} \mathrm{C}$. Mater Sci 21(11):3889-3900

28. Szekely J, Evans JW, Sohn HV (1976) Gas-solid reaction. Academic press, New York

29. Sohn H, Szekely J (1972) A structural model for gas-solid reactions with a moving boundary III: a general dimensionless representation of the irreversible reaction between a porous solid and a reactant gas. Chem Eng Sci 27(4):763-778

30. Seth BL, Ross HU (1965) Mechanism of iron oxide reduction. Trans Metall Soc AIME 233(1):180-185

31. McKewan WM (1960) Kinetics of iron oxide reduction. Trans Am Instit Min Metall Eng 218(1):2-6

32. El-Geassy AA (1996) Reduction of CaO and/or $\mathrm{MgO}$-doped $\mathrm{Fe}_{2} \mathrm{O}_{3}$ compacts with carbon monoxide at 1173-1473 K. ISIJ Int 36(11): 1344

33. S imon P (2004) Isoconversional methods. J Therm Anal Calorim 76(1):123-132

34. Sbirrazzuoli N, Vincent L, Mija A, Guigo N (2009) Integral, differential and advanced isoconversional methods: complex mechanisms and isothermal predicted conversion-time curves. Chemom Intell Lab Syst 96(2):219-226

35. Khawam A, Flanagan DR (2005) Role of isoconversional methods in varying activation energies of solid-state kinetics: I. Isothermal kinetic studies. Thermochim Acta 429(1):93-102

36. Khawam A, Flanagan DR (2005) Role of isoconversional methods in varying activation energies of solid-state kinetics: II. Nonisothermal kinetic studies. Thermochim Acta 436(1):101-112

37. Vyazovkin S (2000) Computational aspects of kinetic analysis: part C. The ICTAC kinetics project-the light at the end of the tunnel. Thermochim Acta 355(1):155-163

38. Burnham $\mathrm{AK}$ (2000) Computational aspects of kinetic analysis, part D: the ICTAC kinetics project-multi-thermal-history model-fitting methods and their relation to isoconversional methods. Thermochim Acta 355(1):165-170

39. Coats A, Redfern J (1964) Kinetic parameters from thermogravimetric data. Nature 201:68

40. Sun Y, Han Y, Wei X, Gao P (2016) Non-isothermal reduction kinetics of oolitic iron ore in ore/coal mixture. J Therm Anal Calorim 123(1):703-715

Publisher's Note Springer Nature remains neutral with regard to jurisdictional claims in published maps and institutional affiliations. 